\title{
Sediment rating and annual cycles of suspended sediment in German upland rivers
}

\author{
Jan Blöthe ${ }^{1}$, Gudrun Hillebrand ${ }^{2}$, and Thomas Hoffmann ${ }^{2, *}$ \\ ${ }^{1}$ Department of Geography, University of Bonn, Meckenheimer Allee 166, 53115 Bonn, Germany \\ ${ }^{2}$ Federal Institute of Hydrology, Am Mainzer Tor 1, 56068 Koblenz, Germany
}

\begin{abstract}
Sediment flux of lowland rivers is dominated by suspended transport, but data is often sparse and analysis largely relies on rating relationships. However, suspended sediment concentration is by no means constant in both, space and time. Here we analyse the variability of sediment rating curves and the seasonality of suspended sediment concentration in German waterways, as recorded by 10 gauging stations with catchment areas between $2600-22000 \mathrm{~km}^{2}$. Our data reveal a distinct break in power-law scaling relationships for all stations, with increased scaling exponents above threshold discharges close to the geometric mean. We attribute this mainly to the activation of sediment sources that resist mobilisation at lower flows. Furthermore, all stations show a counter-clockwise hysteresis effect throughout the year, where summer discharges have a higher sediment load than comparable winter discharges. Though the reasons for this pattern need further investigation, preliminary results show a strong correlation with rainfall erosivity and land-use parameters.
\end{abstract}

\section{Introduction}

Suspended sediment load dominates the sediment transport of almost all lowland rivers of the world and provides an important transport medium for pollutants and contaminants [1, 2]. Achieving a good ecological and chemical status of river systems, as required for instance by the European Water Frame directive, therefore asks for a sound understanding of the sources, transport mechanisms and sinks of suspended sediment. To account for the sediment sources of suspended sediment, a detailed sediment budget including the river catchment is required. Yet, the compilation of catchment-integrated sediment budgets is time consuming and data demanding.

Sediment rating curves are frequently used to analyse potential sources of suspended sediment. Rating curves plot the suspended sediment concentration (SSC) as a function of discharge $\left(Q_{w}\right)$. In many cases, there is a close link between both variables that can be described by a power law:

$$
S S C=a Q_{w}^{b}
$$

where $\mathrm{a}$ and $\mathrm{b}$ are coefficients that depend on the characteristics of the river system. During a single flood event, but also throughout the year, there can be strong deviations from this

\footnotetext{
* Corresponding author: thomas.hoffmann@bafg.de
} 
power-law relationship due to hysteresis effects of the suspended sediment transport. These deviations are typically explained by various sediment sources: i) clock-wise hysteresis (i.e. the $Q_{w}$-peak follows the $S S C$-peak) is observed by a rapid $S S C$-increase, due to withinchannel mobilisation of suspended sediment and subsequent sediment exhaustion, and ii) anti-clock-wise hysteresis results from maximum SSC that follows the $Q_{w}$-peak, due to the long transport distance of sediment sources that are located within the catchment (e.g. arable land on inclined hillslopes with increased soil erosion rates) [3].

While many studies focus on hysteresis effects of SSC during single flood events, much less information is available on seasonal effects and variations of the sediment rating curves throughout the year. Here we hypothesise that spatiotemporal variation of land cover, precipitation, discharge and hydrological soil conditions during a year cause annual hysteresis patterns that are linked to various sources of suspended sediment. We analyse the annual cyclicity and the regional variability of $S S C$ with respect to $Q_{w}$, precipitation, land cover and topographic parameters from 10 selected gauging stations located in five different river basins in Germany, with catchment sizes ranging between 2600 and $\sim 22000 \mathrm{~km}^{2}$ (Fig. 1). All selected catchments are draining the central German uplands and are characterized by roughly comparable topographic relief, median slopes, and mean annual precipitation amounts but cover different lithologies and land use patterns (Tab.1).

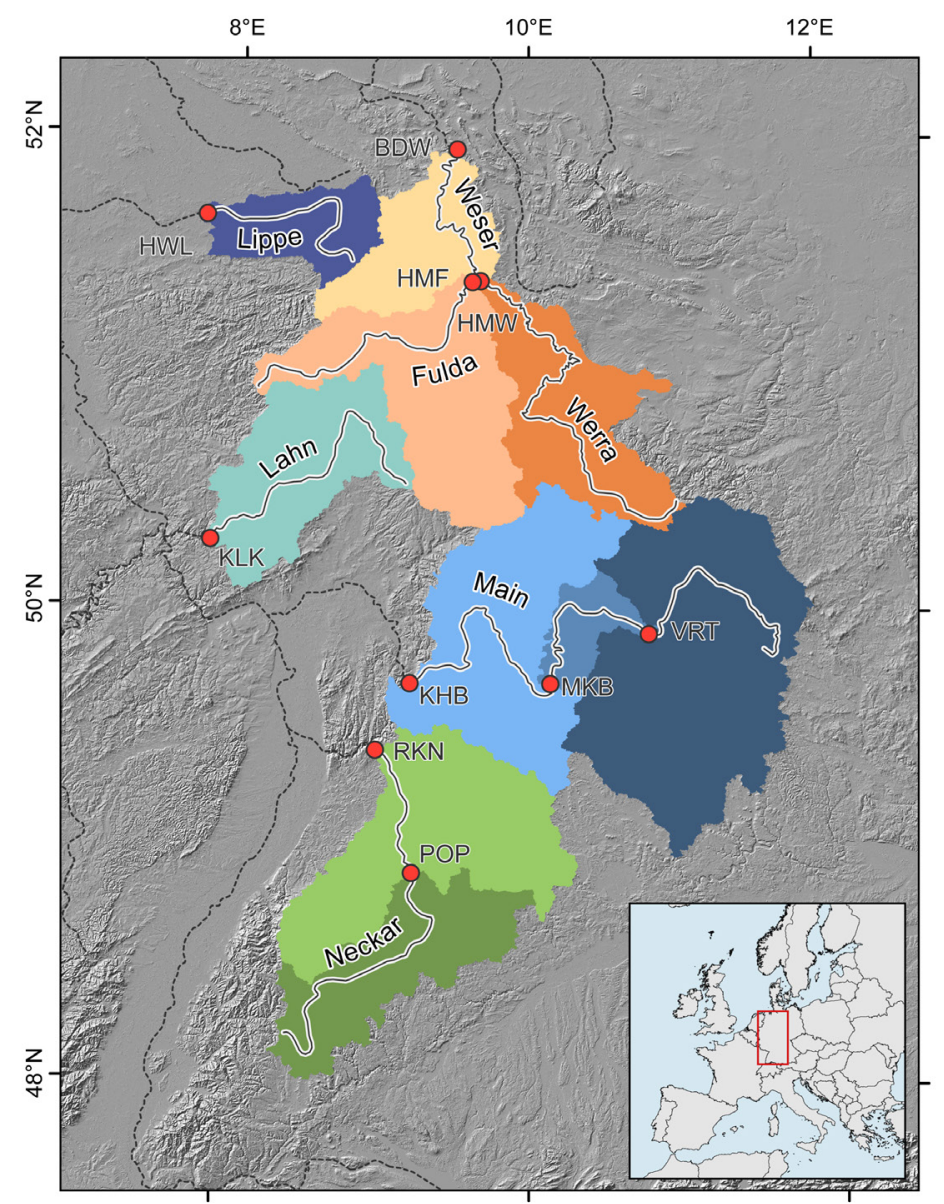

Fig. 1. Major catchments draining the German upland surveyed in this study. For abbreviated catchment names, see Table 1. 
Table 1. Summary of selected gauging stations and their associated catchment's characteristics (see Fig. 1 for location), MQ = mean discharge, SF = sediment flux, SSY = suspended sediment yield, DEM $=$ digital elevation model, SLP $=$ slope, MAP $=$ mean annual precipitation.

\begin{tabular}{|c|c|c|c|c|c|c|c|c|c|}
\hline \multicolumn{4}{|c|}{ Station } & \multicolumn{6}{|c|}{ Catchment } \\
\hline Station name & River & $\begin{array}{c}\text { MQ } \\
{\left[\mathrm{m}^{3} / \mathbf{s}\right]}\end{array}$ & $\begin{array}{c}\text { Mean } \\
\text { SF } \\
{[\mathrm{kg} / \mathrm{s}]}\end{array}$ & $\begin{array}{l}\text { Area } \\
{\left[\mathbf{k m}^{2}\right]}\end{array}$ & $\begin{array}{c}\text { Mean } \\
\text { SSY } \\
{\left[\mathbf{t} / \mathbf{k m}^{2} / \mathbf{a}\right]}\end{array}$ & $\begin{array}{c}\text { DEM } \\
\text { Relief } \\
{[\mathrm{m}]}\end{array}$ & $\begin{array}{l}\text { Median } \\
\text { SLP [ }{ }^{\circ} \text { ] }\end{array}$ & $\begin{array}{c}\text { land } \\
\text { use } \\
{[\%]^{*}}\end{array}$ & $\begin{array}{l}\text { MAP } \\
{[\mathrm{mm}]}\end{array}$ \\
\hline $\begin{array}{l}\text { Hann.-Münden } \\
\text { Werra (HMW) }\end{array}$ & Werra & 51.06 & 3.28 & 5500 & 6846 & 867 & 5.89 & $\begin{array}{l}\text { S } 6 \\
\text { A } 35 \\
\text { V } 59\end{array}$ & 794 \\
\hline $\begin{array}{l}\text { Hann.-Münden } \\
\text { Fulda (HMF) }\end{array}$ & Fulda & 63.78 & 2.22 & 6945 & 3662 & 826 & 5.19 & $\begin{array}{l}\text { S } 6 \\
\text { A } 37 \\
\text { V } 57\end{array}$ & 789 \\
\hline $\begin{array}{l}\text { Bodenwerder } \\
\text { (BDW) }\end{array}$ & Weser & 151.28 & 6.39 & 15943 & 4607 & 918 & 5.24 & $\begin{array}{l}\text { S } 6 \\
\text { A } 37 \\
\text { V } 57\end{array}$ & 797 \\
\hline $\begin{array}{l}\text { Hammer Wehr } \\
\text { (HWL) }\end{array}$ & Lippe & 25.7 & 0.56 & 2589 & 2414 & 560 & 1.51 & $\begin{array}{c}\text { S } 8 \\
\text { A } 25 \\
\text { V } 67\end{array}$ & 864 \\
\hline $\begin{array}{l}\text { Kalkofen } \\
\text { (KLK) }\end{array}$ & Lahn & 45.22 & 2.1 & 5306 & 4316 & 805 & 5.01 & $\begin{array}{c}\text { S } 8 \\
\text { A } 49 \\
\text { V } 43\end{array}$ & 807 \\
\hline Viereth (VRT) & Main & 107.27 & 2.6 & 11981 & 2487 & 811 & 3.69 & $\begin{array}{l}\text { S } 6 \\
\text { A } 28 \\
\text { V } 66\end{array}$ & 800 \\
\hline $\begin{array}{l}\text { Marktbreit } \\
\text { (MKB) }\end{array}$ & Main & 112.99 & 3.96 & 13480 & 3362 & 857 & 3.53 & $\begin{array}{c}\text { S } 6 \\
\text { A } 28 \\
\text { V } 66\end{array}$ & 772 \\
\hline $\begin{array}{l}\text { Kleinheubach } \\
\text { (KHB) }\end{array}$ & Main & 173.81 & 7.33 & 21501 & 3866 & 920 & 3.83 & $\begin{array}{c}\text { S } 6 \\
\text { A } 29 \\
\text { V } 65\end{array}$ & 782 \\
\hline $\begin{array}{l}\text { Poppenweiler } \\
\text { (POP) }\end{array}$ & Neckar & 63.36 & 4.9 & 4969 & 11231 & 820 & 4.23 & $\begin{array}{l}\text { S } 14 \\
\text { A } 42 \\
\text { V } 44\end{array}$ & 912 \\
\hline $\begin{array}{l}\text { Rockenau } \\
\text { (RKN) }\end{array}$ & Neckar & 140.58 & 10.95 & 12673 & 9864 & 893 & 4.06 & $\begin{array}{l}\text { S } 10 \\
\text { A } 36 \\
\text { V } 54\end{array}$ & 911 \\
\hline
\end{tabular}

$* \mathrm{~S}=$ settlement and infrastructure; $\mathrm{A}=$ Agriculture; $\mathrm{V}=$ Forests and artificial non-agricultural vegetated surfaces, including water bodies

\section{Method}

\subsection{Suspended sediment monitoring and analysis}

Suspended sediment in German inland waterways has been monitored using daily water samples taken manually by the Federal Waterways and Shipping Administration (Wasserstraßen- und Schifffahrtsverwaltung des Bundes, WSV) at $\sim 70$ sampling locations. SSC monitoring started in 1965 resulting in long-term records that cover $>30$ years for many stations. At each monitoring site, 5-liter water samples are taken each work day (excluding weekends). During floods the sampling frequency is increased to up to 3 samples per day, unless sampling was prohibited due to safety reasons. Water samples are filtered using commercial coffee filters, which are weighed before and after filtering in dry 
conditions to calculate the daily $S S C\left[\mathrm{~kg} / \mathrm{m}^{3}\right]$ [4]. The application of coffee filters is costefficient and allows to measure $S S C$ at a large number (i.e. 70 samples per day at the national scale) and at sufficient quality. Calculated SSC values presented in this study include both the mineral and organic material of suspended sediment and are therefore equivalent to the concentration of the total suspended solids. Unfortunately, the daily SSCsamples alone do not allow to fractionated the mineral and organic components. The suspended sediment samples are take close to the water surface (at maximum $1 \mathrm{~m}$ water depth) and mainly contains clay and silt and only a small fraction of fine sand (on average we assume a sand content of $\sim 9 \%$ ). An impact of the bedload (i.e. mainly coarse sand and gravel) on the sampled suspended sediment can therefore be neglected.

From these data, we calculate sediment rating curves following Eq. 1. The interpretation of the coefficients $a$ and $b$ in Eq. 1 is complicated by the dependence of $a$ upon the discharge units, i.e. $a$ has the units of $\mathrm{MT}^{\mathrm{b}} \mathrm{L}^{-(1+3 b)}$, and upon $b$. To avoid this complication and to be able to compare the results of the rating curves of all stations investigated, $S S C$ and $Q_{w}$ values are normalized using their geometric means according to Warrick [5]:

$$
S S C / S S C_{G M}=a\left(Q_{w} / Q_{w, G M}\right)^{b}
$$

In many cases, there is a distinct break in the sediment rating curve, with different rating domains above and below this break. To estimate the discharge $\left(Q_{w, t h}\right)$ at which this break occurs, we use the locally weighted scatter smoothing (lowess) regression curve [6]. Furthermore, we use two log-linear regressions of $S S C / S S C_{G M}$ and $Q_{w} / Q_{w, G M}$ below and above $Q_{w, t h} . Q_{w, t h}$ is then given to optimize the regression above and below $Q_{w, t h}$ (i.e. by maximizing the sum of both $\mathrm{R}^{2}$ ).

Furthermore, intra-annual variations of $S S C$ versus $Q_{w}$ are analysed using long-term averages of $S S C / S S C_{G M}$ and $Q_{w} / Q_{w, G M}$ and are discussed on terms of the seasonal variations of vegetation and precipitation.

\subsection{Spatiotemporal variability of catchment averaged land use, vegetation and precipitation}

To further investigate the causes of spatiotemporal variability of SSC in German upland rivers, we compile basin-averaged values of the normalized difference vegetation index (NDVI), gridded precipitation data and information on land cover change. Given the temporal coverage of our data set (between 33 and 50 continuous years), we aimed for data sets that span a comparable time range. For precipitation, we used the REGNIE (regionalised precipitation) data set provided by the German weather service (ftp://ftpcdc.dwd.de), a spatially interpolated data set available at daily resolution from 1931 to 2014 [7]. For vegetation, we used the global vegetation index and phenology data set (VIP30) that combined AVHRR and MODIS data [8]. Furthermore, we analysed rainfall erosivity [9], Corine land cover data (1990-2012) and a 25x25 m digital elevation model (EU-DEM v1.1) provided by the European Joint Research Council (https://land.copernicus.eu).

\section{Results}

Despite roughly comparable topographic signatures (and a close juxtaposition), catchments of similar size show strong contrasts in specific sediment yields (SSY). Especially the gauging stations along the Neckar (POP and RKN) record SSY that exceed the values of similarly sized catchments (e.g. KRK and MKB, respectively) by a factor of three. Both stations belonging to the Neckar river system (POP and RKN) that drains the Swabian 
escarpment record by far the largest average $S S Y$, despite having comparable topographic relief and median slope values as the majority of catchments (Tab. 1).

\subsection{Sediment rating}

The sediment rating curves of all stations investigated do not show simple power law relationships but are characterized by a distinct break of the power law at a threshold discharge $Q_{w, t h}$ (Fig. 2). This dual power law is characterized by a break close to the geometric mean discharge, with positions ranging between $0.74<Q_{w, t h} / Q_{w, G M}<1.65$, around a mean value of 1.25 . Since the geometric mean discharge is in the range between 75 to $85 \%$ of the average $Q_{w}$, the break in the power law is closely linked to the average discharge. The minimum and maximum values of the scaling exponent are -0.53 and 0.26 below $Q_{w, t h}\left(\mathrm{~b}_{\text {down }}\right)$ and 0.67 and 1.50 above $Q_{w, t h}\left(\mathrm{~b}_{\text {up }}\right)$, respectively.

\section{Rockenau (Neckar)}

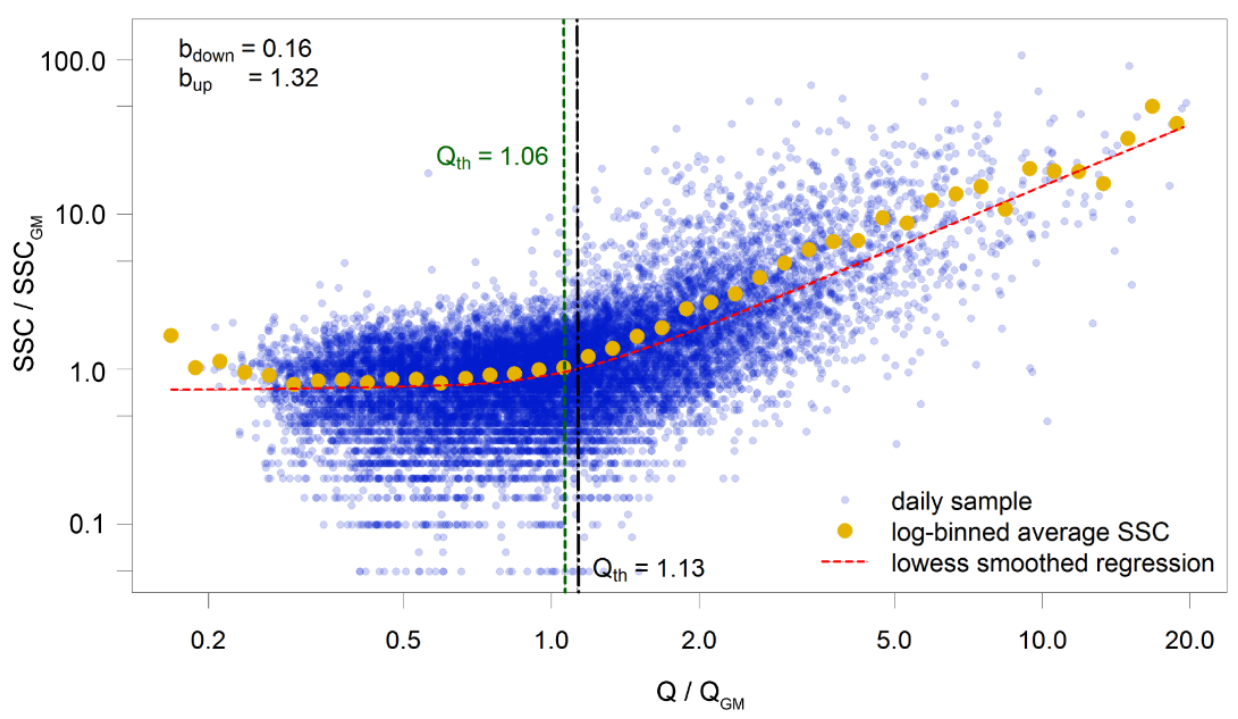

Fig. 2. Normalized suspended sediment concentration $\left(S S C / S S C_{G M}\right)$ versus normalized discharge $\left(Q_{w} / Q_{w G M}\right)$ for station Rockenau between 1972-2011. Blue dots indicate daily samples, large yellow dots show log-binned average values for $S S C / S S C_{G M}$. Thin red dashed line shows lowess smoothed regression, vertical green (dashed) and black (dotted-dashed) lines indicate threshold values of $Q_{w} / Q_{w G M}$, determined form maximum curvatures of lowess regression line and crossing point from two log-linear regressions, respectively.

\subsection{Annual sediment hysteresis}

All ten stations show a counter-clockwise hysteresis throughout the year, with the summer month (JJA) showing the highest ratio of $S S C / Q_{w}$ at most stations, compared to reduced ratios during the winter months (DJF) (Fig. 3). The absolute average SSC values at most stations show a twofold increase during the summer months, while $Q_{w}$ is dropping by a factor of three. This pattern does not change, despite the differences in lithology, precipitation, land cover, basin size and basin topographic signature. 


\section{Bodenwerder (Weser) 1965 - 2014}

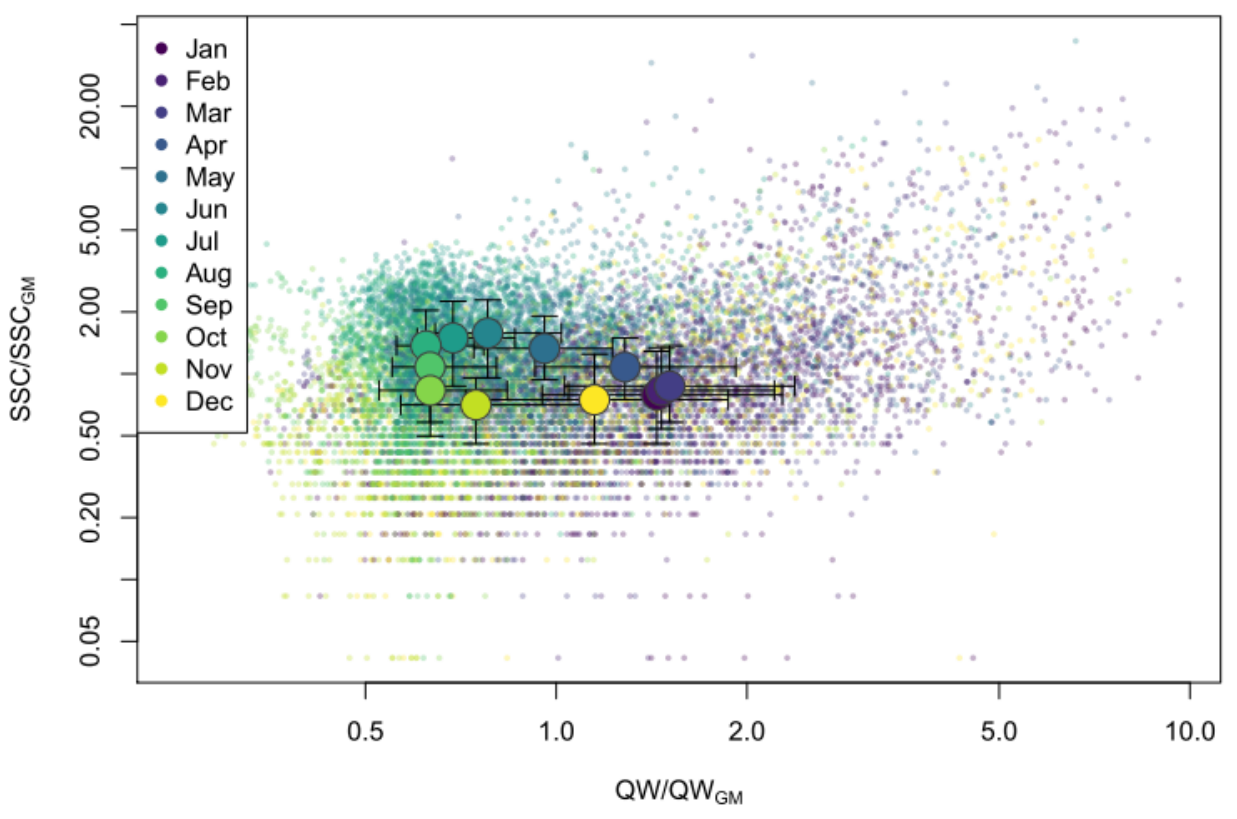

Fig. 3. Normalized suspended sediment concentration $\left(S S C / S S C_{G M}\right)$ versus normalized discharge $\left(Q_{w} / Q_{w G M}\right)$ colour coded by month for station Bodenwerder between 1965-2014. Large circles show monthly averages of 50 -year record with error bars spanning $25^{\text {th }}$ to $75^{\text {th }}$ percentile.

\section{Discussion and conclusions}

The large differences in average $S S Y$ that we find for catchments of similar size and similar topographic relief are remarkable. We note, however, that all stations are characterized by a strong variability in SSY during the time recorded, with extreme years exceeding the longterm mean by more than $150 \%$. Furthermore, there is only a weak correlation (all R-values below 0.5 ) between $S S Y$ and total $Q_{w}$. Judging from our data, land cover plays an important role for the $S S Y$ delivered from a catchment, we find a strong negative correlation $(\mathrm{R}=-0.65)$ between the percentage of forest cover and SSY. Especially highintensity rainfall events from convective summer storms can mobilize large amounts of material, if protective vegetation cover is absent [10].

The counter-clockwise hysteresis found at all stations might be caused by this high rainfall erosivity of convective summer precipitation that is further enhanced by agricultural land-use in Germany, as fields with double-cropping are harvested in early summer and hence leave bare surfaces unprotected against the erosive runoff (Fig. 3). This notion is further supported by the strong correlation between modelled rainfall erosivity values [9] and the increased SSC values during the summer months (Fig. 4; average correlation coefficient for all stations $\mathrm{R}=0.71$ ). However, the distinct break in the power law relationship that our data reveals is probably not related to this effect, as the majority of values plotting above $Q_{w, t h}$ are recorded in the winter months (Fig. 2). Here we argue that this break in power law close to the mean discharge might have three causes: 
Poppenweiler (Neckar) data averages 1966 - 2010

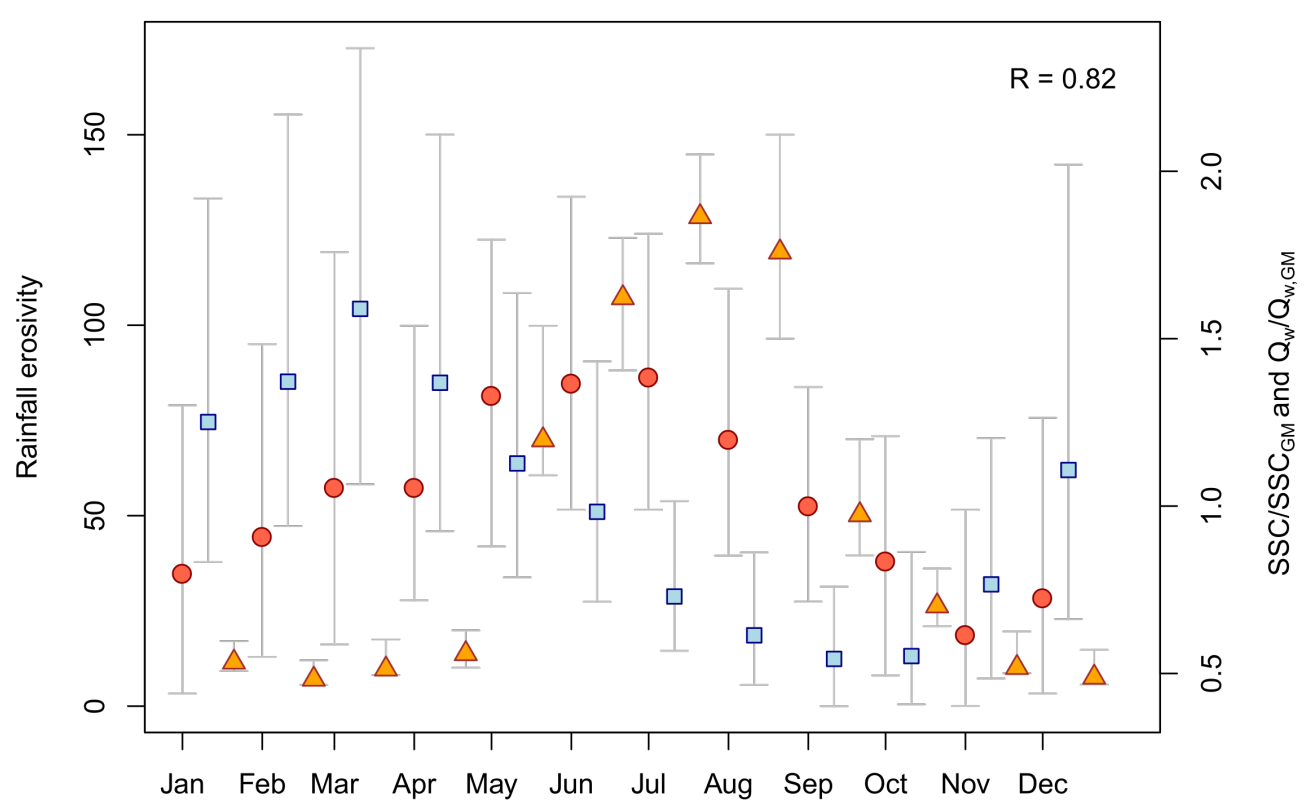

Day of year

Fig. 4. Long-term averages of rainfall erosivity (orange triangles; [9]), $Q_{w}$ (blue squares), and SSC (red circles) for gauging station at Poppenweiler. Error bars give $25^{\text {th }}$ and $75^{\text {th }}$ percentile of the value distribution, regression coefficient in upper right corner gives Pearson regression coefficient between rainfall erosivity and $S S C$.

First, the increase of the scaling exponent can be attributed to the mobilisation of sediment sources that are activated by flood discharges during the winter.

Second, we analyse total suspended sediment, which includes both organic and mineral suspended matter. The organic matter content of the suspended sediment is typically negatively related to discharge. Thus the scaling exponent of the organic suspended sediment $S S C_{\text {org }}$ is generally lower than that of the mineral fraction $S S C_{\min }$. Therefore the total $S S C$ can be estimated using the sum of the organic and mineral fraction:

$$
S S C_{\text {tot }}=S S C_{\text {min }}+S S C_{\text {org }}=a_{\text {min }} Q_{w}^{b_{\text {min }}}+a_{\text {org }} Q_{w}^{b_{\text {org }}}
$$

with $b_{\text {org }}<b_{\text {min. }}$. At small discharge the scaling off $S S C_{\text {tot }}$ approaches $b_{\text {org }}$, while at large discharges $S S C_{\text {tot }}$ scales with $b_{\text {min }}$. This hypothesis is supported by unpublished data from two stations located in Koblenz at the rivers Mosel and the Rhine, where the $b_{\text {min }} / b_{\text {org }}$ ratio is roughly 1.5 for both stations.

Third, many waterways, including all rivers considered in this study, are controlled by barrages. Hydropower plants as part of many barrages are often designed for mean discharges. Thus, opening of the gates during high flows and remobilisation of sediment deposited upstream of these barriers may explain the change in regression exponents above $Q_{w, t h}$. The relative importance of these three causes needs further investigation and will be presented at the River Flow conference.

Further research is required to identify the relative importance of these three mechanisms to explain the scaling-break of the total suspended sediment concentration in the German waterways. 


\section{Acknowledgement}

The authors would like to thank the German Waterways and Shipping Administration for providing the data on suspended sediment loads.

\section{References}

1. P.S. Naden. Sediment Cascades: The Fine-Sediment Cascade. (John Wiley \& Sons, Ltd, Chichester, UK, 2010)

2. D.E. Walling, Geomorphology, 79 (2006)

3. N.E. Asselman, J Hydrol, 234 (2000)

4. G. Hillebrand, Proc. Karlsruher Flussgebietstage (2013)

5. J.A. Warrick Hydrol. Process., 29 (2015)

6. W.S. Cleveland, J. Am. Stat. Assoc., 74 (1979)

7. M. Rauthe, H. Steiner, U. Riediger, A. Mazurkiewicz, A. Gratzki, Meteorol. Zeitschrift, 22 (2013)

8. K. Didan, NASA EOSDIS L Process DAAC (2014)

9. $\quad$ C. Ballabio et al., Sci. Total Environ., 579 (2017)

10. J. Nyssen et al., J. Hydrol., 311 (2005) 